\title{
Chronic kidney disease
}

\author{
Mai Ots Rosenberg \\ Tartu University \\ Estonia
}

\section{Introduction}

Chronic kidney disease (CKD) is increasingly recognized as a major public health problem. CKD is often under-diagnosed and under-treated because the disease tend to be latent at onset and progress slowly. High blood pressure, diabetes and primary or secondary glomerulonephritis are the main causes of CKD. Today, various diabetic and non-diabetic glomerulopathies form the main contingent of renal replacement therapy (RRT) patients. The above named diseases, therefore, present a major problem encountered in the practice of nephrology. CKD affects many more people than we would even imagine: 1 out of 10 adults in the world have some form of kidney damage. Therefore, early detection and prevention the progression of people with CKD who are also at very high cardiovascular risk, is extremly important challenge and goal especially for all internal medicine practitioners.

CKD represents a progressive, irreversible decline in glomerular filtration rate. Progressive renal function loss is a common phenomenon in renal failure irrespectively of the underlying cause of the kidney disease (Brenner and Anderson 1992; Ots, Pechter et al. 2000). The kidney is able to adapt to damage by increasing the filtration rate in the remaining normal nephrons, a process called adaptive hyperfiltration. As a result, the patient with mild renal insufficiency often has a normal or near-normal serum creatinine concentration. Adaptive hyperfiltration, although initially beneficial, appears to result in long-term damage to the glomeruli of the remaining nephrons, which is manifest by proteinuria and progressive renal insufficiency. This process appears to be responsible for the development of renal failure among those in whom the original illness is either inactive or cured (Post and Rose 2007). Most chronic nephropathies unfortunately lack a specific treatment and progress relentlessly to end stage renal disease. The therapy for the modulation of the renal disease progression has been improved lately because several new antihypertensive drugs which block renin-angiotensin system (RAS) have been introduced to clinical practice, e.g. angiotensin converting enzyme inhibitors (ACEI) (Rubin, Antonaccio et al. 1978) and angiotensin II receptor antagonists (AT $\left.\mathrm{A}_{1} \mathrm{RA}\right)$. ACEI proved its effectiveness in the treatment of essential hypertension and congestive heart failure. Later, studies on experimental (Anderson, Meyer et al. 1985) and human diabetic (Lewis, Hunsicker et al. 1993; Brenner, Cooper et al. 2001) and non-diabetic (Maschio, Alberti et al. 1996) renal diseases revealed that the progression of the renal disease can be slowed by RAS blocking treatment that modulates the hemodynamic and non-hemodynamic factors contributing to 
the progression. RAS blocking agents have been shown to be renoprotective and, therefore, prescribed not only for antihypertensive but also for renoprotective purposes in diabetic nephropathy and in other chronic glomerular diseases. The cost of the advanced renal failure and renal replacement therapy is enormous. Therefore, early diagnosis and optimal management of CKD as well as premature atherosclerosis affords many challenges for internal medicine practitioners to help to maintain health and life quality among the population at risk.

\section{Epidemiology of CKD}

There is a rising incidence and prevalence of kidney failure and the worldwide epidemic of CKD shows no signs of abating in the near future. The exact reasons for the growth of the end-stage renal disease are unknown. Changes in the demographics of the population, differences in disease burden among different racial groups and under-recognition of earlier stages and of risk factors for CKD may partially explain this growth. Recent trends show that the rate of increase of new cases of both diabetic and all-cause end-stage renal disease (ESRD) has progressively levelled off in many countries. It is therefore currently impossible to predict the long-term trend of RRT in Europe (Zoccali, Kramer et al.). Zocalli et al have recently acknowledged that in the large, diachronic scenario of systemic epidemiology, CKD is a component of a new epidemic of diseases that, over the twentieth century, replaced malnutrition and infection as leading causes of mortality in the population (Zoccali, Kramer et al.). Neoplasia, cardiovascular and respiratory diseases and diabetes are ascending the priority rank in the global-health agenda. These diseases reduce life expectancy and engender disability in all population strata including the poorest segment of the population, a stratum still considered to be mainly hit by infectious diseases (Zoccali, Kramer et al.).

The ERA-EDTA Registry (http://www.era-edta-reg.org) collects individual and aggregated data from national and/or regional renal registries in Europe and countries bordering the Mediterranean Sea. The individual patient data are used for epidemiological analysis to calculate incidence, prevalence and patient survival. These are published in the Registry annual reports together with aggregated incidence and prevalence data that are received from other European countries.

Diabetes is one of the commonest causes of CKD beside hypertension and glomerulonephritis in many countries (Locatelli, D'Amico et al. 2001; Moeller, Gioberge et al. 2002; Jager and van Dijk 2007). The major groups of diseases leading to ESRD are diabetic nephropathy, hypertension, glomerulonephritis, chronic pyelonephritis and polycystic kidney disease. In different countries the proportions of these diseases as a cause of renal failure vary: e.g. prevalent patients of diabetic nephropathy form from RRT patients in Italy $12 \%$, in Estonia 22\%, in Finland and Poland 24\%, in Germany 23\%, in England 12\%, in Japan $30 \%$, and in USA $37 \%$. Very few of the causes of CKD are completely curable. Glomerulonephritis form 22-24\% from prevalent renal replacement therapy (RRT) patients in Estonia, Germany, Poland or Finland but only 11-12\% in France, Italy or England.

The use of RRT varies in different countries. The prevalence of RRT patients/million inhabitants 2005 was very different worldwide: in Estonia 394, in Finland 675, in Sweden 774, in Germany 1057, in Spain 869, in England 671 or in USA 1590.

It has been shown that CKD affects men more often than women. For example, according to the Finnish Registry for Kidney Diseases the prevalence of RRT in men was 898 and in 
women 553/million inhabitants in 2006. Since 1996, the prevalence of RRT has increased faster among men $(63 \%)$ than among women $(44 \%)$. The prevalence among the elderly is growing fast: in the age group 75+ years, the prevalence of RRT has increased by almost $250 \%$ during the past ten years and $70 \%$ during the past five years. In the younger age groups, the prevalence has increased $10-61 \%$ in ten years and $4-14 \%$ in five years.

\section{Progression of CKD}

Several immunologic as well as non-immunologic mechanisms are related to the progression of kidney diseases (Klahr, Schreiner et al. 1988; Remuzzi, Ruggenenti et al. 1997). The nature of the progressive renal damage with various etiologies includes well-known factors where hemodynamics (Hostetter, Olson et al. 1981), participation of RAS and progressive proteinuria (Williams and Coles 1994)play central roles (Remuzzi, Ruggenenti et al. 1997).

In chronic renal failure, after the loss of a critical number of nephrons, the remaining nephrons undergo compensatory functional and structural adaptations. During this process, the surviving nephrons lose the capacity to autoregulate glomerular flows and pressures and become vulnerable to the effects of systemic hypertension, which is readily accompanied by glomerular hypertension, hyperfiltration and hypertrophy (Hostetter, Olson et al. 1981). Angiotensin II is important in mediating glomerular hemodynamics and contributes to the rise of intraglomerular and systemic blood pressure. In essential and secondary hypertensive states, at a certain stage, an increase in intraglomerular capillary pressure plays a role in the acceleration of the loss in renal function. Hypertension is a risk factor for the development of atherosclerosis (Ross 1986), for all-cause mortality (O'Donnell, Ridker et al. 1997), but also of glomerulosclerosis in various etiologies (Klag, Whelton et al. 1996). These two processes share several common mechanism (Diamond 1991), e.g. hormonal, cellular and molecular events although these have not been entirely elucidated. Central to the pathogenesis of atherosclerosis is the interaction of blood cells and endothelial cells with subsequent proliferation of smooth muscle cells and enhanced production of collagen. The mechanisms that appear to be responsible for this increased proliferative response are growth factors, cytokines, and local alterations in the extracellular matrix proteins. There is increasing evidence that atherosclerosis should be viewed fundamentally as an inflammatory disease (Raines and Ross 1997) where risk factors such as hypertension, humoral factors (Raij 1991), hyperlipidemia (Devaraj and Jialal 1996), lipid deposition in vessels and later development of atherosclerotic lesions play central roles in the progression. As in the case of atherosclerosis, there is an inflammatory content involved in kidney fibrosis in human (Noronha, Niemir et al. 1995) or experimental glomerulonephritides (Lloyd, Minto et al. 1997), and even in classical glomerulosclerotic models previously thought to be non-inflammatory, e.g. remnant kidney (Schiller and Moran 1997). Infiltration of mononuclear leucocytes in glomerular and tubulointerstitial areas, upregulation of proinflammatory cytokines and growth factors after the initiation of the disease play important roles in the progression (Schiller and Moran 1997). The glomerulosclerosis process includes mesangial expansion with mesangial cell proliferation, mesangial foam cell accumulation, tissue necrosis, and eventual sclerosis. Substances that interfere with the interaction between the different cell types, such as endothelial cells, macrophages, and platelets, and with the proliferative responses of both vascular and mesangial cells may be of therapeutic value in both diseases. 
Data about the upregulation of various proinflammatory cytokines are similarly available for other non-inflammatory renal diseases such as diabetic nephropathy and certainly for human nephropathies (Niemir, Stein et al. 1995; Kato, Luyckx et al. 1999). Wagner et al. provided technical evidence that using PCR may give a possibility in the future to analyze expressions of genes which may contribute to renal damage in human biopsies (Wagner, Drab et al. 1994). Knowing key molecules, which play a pathophysiological role or serve as markers for the progression of renal disease may allow more precise staging of the disease and better indicate therapeutic needs in particular diseases. Cytokines have also been demonstrated in other biological samples, e.g. urine. The results of Noh et al. (Noh, Wiggins et al. 1993) suggest that measurements of urinary activity of transforming growth factor beta (TGF- $\beta$ ) at certain critical stages of the disease could be useful in predicting the progression to end-stage renal disease with fibrosis. Therefore, a urine test for the detection of particular growth factors might serve as a helpful non-invasive adjunct in monitoring the response to therapy. Much interest has been paid to TGF- $\beta$ because the key action of this growth factor is the induction of the extracellular matrix protein production. Specific matrix proteins are known to be induced by TGF- $\beta$, which were increased in experimental kidney disease rat glomeruli. For instance, Yamamoto et al. has shown the correlation of TGF- $\beta$ (Yamamoto, Noble et al. 1994) with the accumulation of extracellular matrix proteins in the glomerulonephritis model and the treatment with the inhibitor of TGF- $\beta$ prevents scarring of the kidney. Yamamoto et al. were able to show that in the rats given a second antibody injection of an antibody reactive with glomerular mesangial cells, 1 week later, the glomerular expression of TGF- $\beta-1$ mRNA and TGF- $\beta-1$ protein remained elevated for 18 weeks. It was associated with a large infiltration of mononuclear cells with staining features of fibroblastic/myofibroblastic cells, strongly expressing TGF- $\beta$ in the tubulointerstitium of the kidney (Yamamoto, Noble et al. 1994). A single injection of antibody resulted only in the transient upregulation of TGF- $\beta$. These data suggest that sustained TGF- $\beta$ expression contributes to the development of progressive kidney fibrosis. TGF- $\beta$, monocyte chemoattractant protein-1 (MCP-1) mRNA and protein expression as well as macrophage infiltration dynamics have been investigated in experimental diabetic nephropathy (Kato, Luyckx et al. 1999). In these studies sustained TGF- $\beta$ and MCP-1 overexpression was also observed. This particular gene expression was closely associated with the extent of macrophage infiltration and proteinuria (Kato, Luyckx et al. 1999).

Much attention has recently been paid to the importance of persistent proteinuria, an independent risk factor of renal disease progression (Klahr, Schreiner et al. 1988; Williams and Coles 1994). Proteins filtered through the glomerular capillary in excessive amount activate proximal tubular cells to upregulate chemokines mainly via activation of NFkappaB-dependent pathway. The association between proteinuria and interstitial accumulation of inflammatory cells via activation of transcription factors and overexpression of chemokines has been established both experimentally and in human proteinuric nephropathies (Zoja, Garcia et al. 2009). Biochemical events associated with tubular cell activation in response to protein stress include upregulation of inflammatory and vasoactive genes such as MCP-1 and endothelins. These molecules are associated with a tubulointerstitial inflammatory reaction that in most forms of glomerulonephritis consistently proceeds renal scarring. Adequate early antiproteinuric therapy may arrest the progression of the renal disease or even lead to the regression of the disease. Also, disturbances in lipid metabolism, participation of cellular and molecular factors and 
subsequent accumulation of extracellular matrix components with the development of kidney fibrosis are closely related to the progression (Floege, Burns et al. 1992; Remuzzi, Ruggenenti et al. 1997). Clarification of the mechanisms underlying progression of proteinuric nephropathies received significant input from the generation of transgenic and knockout animals and from novel approaches to block mediators of injury. Recent findings have shown that gene targeting in rodents identified podocyte loss as central event in the development of glomerulosclerosis. The trigger is dysfunction or absence of podocyte molecules that stabilize the slit diaphragm or anchor foot processes to the basement membrane. Sustained injury of the glomerular barrier to proteins is transmitted to the tubulointerstitial compartment leading to inflammation and fibrosis. Blocking NF-kappaB activity and chemokine signals in the kidney effectively interrupts such process. Growth factors produced by tubular cells and inflammatory cells contribute to interstitial fibrogenesis via myofibroblast activation. This knowledge will provide basis for novel interventions to protect the podocyte in chronic progressive glomerulopathies and to halt renal scarring and loss of function (Zoja, Abbate et al. 2006).

\section{CKD progression prevention strategies}

Various therapies have been studied which may protect kidneys against progressive injury including at least two experimentally and clinically confirmed strategies: a reduction in protein intake (Brenner, Meyer et al. 1982) or a lowering in blood pressure (Anderson, Meyer et al. 1985). Systemic hypertension complicates experimental glomerulosclerosis and the clinical course of patients with chronic renal failure, and, if inadequately controlled, may hasten the deterioration of renal function (Klag, Whelton et al. 1996). In diabetic and nondiabetic patients with proteinuria controlling blood pressure with RAS blocking agents slows significantly the rate of the decline of the glomerular filtration rate (GFR).

Other cardiovascular risk factors also play important roles in the progressive renal disease. Beside hypertension, smoking (Orth 2000), obesity or hyperlipidemia has not been intensively investigated in the early stages of renal disease. Usually hyperlipidemia is thought to be associated more with ongoing atherosclerotic process. Nevertheless, experimental studies have been shown that lipid abnormalities themselves can influence the progression of renal disease and lipid oxidation is increased in animal and human glomerular disease. Increased nephron oxygen radical generation leads to renal tissue lipid peroxidation. On the other hand, antioxidative therapy has been shown to be effective on antioxidative status in experimental diabetes and in human hypertension. Antilipemic therapy may also be beneficial in ameliorating renal disease progression.

It has been shown that the inhibition of TGF- $\beta$ leads to the protection of scarring in experimental kidney diseass. The modulation of the human renal disease process with inhibiting directly particular cytokine upregulation or even prevent fibrotic events, awaits future confirmation studies.

The concept of nephro- or renoprotection as a definitive proof of ACEI for superior efficacy on systemic and intraglomerular pressure, proteinuria and renal disease progression was not defined until the results of clinical trials became available. It is proposed that in treating hypertension we should aim at reducing systemic blood pressure together with an attempt to reduce intraglomerular pressure using the agents that act predominantly on postglomerular resistance in order to have renal protection. Both RAS blocking drugs, ACEI and 
$\mathrm{AT}_{1} \mathrm{RA}$ have achieved these parameters, and the renoprotective effect includes their impact on the hemodynamics, on the reduction of the filtration of plasma proteins, on the preservation of kidney function as well as the structure. Therefore, these agents have already been accepted in the treatment of diabetic and non-diabetic nephropathies in order to arrest and/or prevent renal damage.

There is convincing evidence that beside diuretics, adrenoblocking agents, beta-blockers, calcium channel blockers and other antihypertensive medications, administration of RAS blocking agents promise better control of glomerular hypertension and long-term outcome of kidney preservation than other agents. Moreover, experimental as well as clinical data suggest that ACEI reduce proteinuria and retard the progression of the renal disease to a greater degree than can be explained by their blood pressure lowering effects alone. Effective blockade of RAS with ACEI preventing sustained elevation of systemic blood pressure, lowering intracapillary pressure, lowering proteinuria modulating hyperlipidemia and inhibition of renal growth have been shown to reduce kidney injury and protect the kidney even further during the ongoing disease process. The ACEI, by decreasing angiotensin II generation, induce glomerular efferent arteriolar dilation as well as mesangial relaxation. These combined effects explain a reduced glomerular capillary pressure. The fall in filtration pressure contributes to the antiproteinuric effect and also to the long-term renoprotection.

Glomerulosclerosis and interstitial fibrosis that accompany experimental and human glomerulopathies can also be ameliorated by ACEI or $\mathrm{AT}_{1} \mathrm{RA}$ administration. Proteinuria itself is involved in the final common pathway of the progressive renal function loss. It has been hypothesized that the presence of large quantities of protein within the tubules may have a damaging effect on the tubular cells and interstitium. This is particularly relevant since attention has recently been focused on a well-known but an ignored fact that the progression of renal disease best correlates with the extent of interstitial damage and not with glomerulosclerosis per se. Remuzzi et al. have summarized the evidence that the process of reabsorption of filtered proteins activates the proximal tubular epithelium (Remuzzi, Ruggenenti et al. 1997).

Most experimental studies that compared the effects of ACEI and $\mathrm{AT}_{1} \mathrm{RA}$ have shown a striking similarity of actions between these classes of drugs. Similarly, the effect of ACEI, AT 1 RA has also been shown to lower the systemic and intraglomerular pressure as well as proteinuria and morphological lesions. Combination therapy with ACEI and $\mathrm{AT}_{1} \mathrm{RA}$ is similar to those of enalapril or losartan alone and are related to the magnitude of their systemic antihypertensive effects (Ots, Mackenzie et al. 1998). These results indicate that both ACEI and AT 1 RA can lower blood pressure at least as effectively as ACE inhibitors and also be renoprotective. In diabetic and non-diabetic patients with proteinuria controlling blood pressure with RAS blocking agents slows significantly the rate of the decline of the glomerular filtration rate (GFR) (Mogensen, Keane et al. 1995). Moreover, the treatment has good effect also for cardiovascular outcome of patients with $\mathrm{CKD}$ (Brenner, Cooper et al. 2001). In conclusion, many recent experimental and clinical studies have shown that besides the systemic blood pressure lowering effect, RAS blocking agents provide renal protective effects via direct, hemodynamic, and indirect, nonhemodynamic, pathways: (1) lowering intraglomerular capillary hydraulic pressure, and increasing the glomerular ultrafiltration coefficient; (2) lowering proteinuria; (3) lowering hyperlipidemia; (4) diminishing kidney growth; (5) diminishing infiltration of macrophages; (6) downregulation of proinflammatory cytokines. Therefore, RAS blocking agents are widely prescribed not only for antihypertensive but also for renoprotective purposes in diabetic and 
non-diabetic nephropathies. In order to slow to the greatest extent progression of renal disease, the ideal therapeutic approach for patients with proteinuric nephropathies should be a multimodal strategy including dual RAS blockade, antialdosterone therapy, lipid-lowering agents, smoking cessation, and tight glucose control for diabetes.

\section{Management of CKD patients}

Clinical evaluation for CKD should include elucidation of the cause of disease. Also, for determining the stage and specific characteristics of the underlying disease follow-up of patients and thorough diagnostic work-up is needed. However, the cause of the disease cannot be ascertained in all cases because renal function declines also normally with age and the exact level of decline at a given age that should be considered pathological is not known. Cross-sectional studies report a slow decline in GFR after the fourth decade of life $\sim 0.75$ $\mathrm{mL} / \mathrm{min} . / 1.73 \mathrm{~m}^{2} /$ year. These changes proceed slowly but in the presence of other diseases such as diabetes, hypertension and heart disease, the kidney becomes vulnerable to failure (Pannu and Halloran 2001). The KD:IGO (Kidney Disease: Improving Global Outcomes) statement considers GFR less than $60 \mathrm{~mL} /$ minute pathological at all ages. CKD is classified according to severity, diagnosis, treatment and prognosis. Five-stage classification is based on structural and functional criteria regardless of the cause and accounting for dialysis and transplantation (Gregorio, Obrador et al. 2007).

The National Kidney Foundation-Kidney Disease Outcomes Quality Initiative (NKF-K/DOQI) workgroup has defined CKD as the following (2002), which have been accepted internationally with some clarifications (Levey, Eckardt et al. 2005; Gregorio, Obrador et al. 2007):

1 The presence of markers of kidney damage for 3 months, as defined by structural or functional abnormalities of the kidney with or without decreased glomerular filtration rate (GFR), that can lead to decreased GFR, manifest by either pathological abnormalities or other markers of kidney damage, including abnormalities in the composition of blood or urine, or abnormalities in imaging tests

2 Or the presence of GFR $<60 \mathrm{~mL} / \mathrm{min}$./ $1.73 \mathrm{~m}^{2}$ for 3 months, with or without other signs of kidney damage as described above.

Based upon representative samples of the United States population (2002), the studies have estimated the prevalence of CKD in the general population through measurement of markers of kidney damage, such as elevated serum creatinine concentration, decreased predicted GFR and presence of albuminuria.

According to the Kidney Disease: Improving Global Outcomes (KD:IGO) position statement the use of the term "disease" in CKD is consistent with:

1) the need for action to improve outcomes through prevention, detection, evaluation and treatment;

2) providing a message for public, physician and patient education programs;

3) common usage; and

4) its use in other conditions defined by findings and laboratory tests, such as hypertension, diabetes and hyperlipidaemia (Levey, Eckardt et al. 2005).

CKD is classified according to severity, diagnosis, treatment and prognosis (Levey, Eckardt et al. 2005). Five-stage classification is based on structural and functional criteria regardless of the cause and accounting for dialysis and transplantation (Table 1). 


\begin{tabular}{|l|l|l|l|}
\hline Stage & Description & GFR $\left(\mathrm{mL} / \mathrm{min}\right.$. per $\left.1.73 \mathrm{~m}^{2}\right)$ & Related terms \\
\hline 1 & $\begin{array}{l}\text { Kidney damage } \\
\text { with normal or } \uparrow \\
\text { GFR }\end{array}$ & $\geq 90$ & $\begin{array}{l}\text { Albuminuria } \\
\text { Proteinuria } \\
\text { Haematuria }\end{array}$ \\
\hline 2 & $\begin{array}{l}\text { Kidney damage } \\
\text { with mild } \downarrow \text { GFR }\end{array}$ & $60-89$ & $\begin{array}{l}\text { Albuminuria } \\
\text { Proteinuria } \\
\text { Haematuria }\end{array}$ \\
\hline 3 & Moderate $\downarrow$ GFR & $30-59$ & $\begin{array}{l}\text { Chronic renal } \\
\text { insufficiency } \\
\text { Early renal } \\
\text { insufficiency }\end{array}$ \\
\hline 4 & & & $\begin{array}{l}\text { Chronic renal } \\
\text { insufficiency } \\
\text { Late renal } \\
\text { insufficiency } \\
\text { Pre-ESRD }\end{array}$ \\
\hline 5 & Severe $\downarrow$ GFR & $15-29$ & $\begin{array}{l}\text { Renal failure } \\
\text { Uraemia } \\
\text { End-stage } \\
\text { renal disease }\end{array}$ \\
\hline
\end{tabular}

Table 1. Classification of chronic kidney disease.

There is an overwhelming consensus that screening for CKD should include high-risk groups. Early detection of diabetes and hypertension as the most important reasons for CKD and their appropriate treatment is a method of avoiding or postponing complications, incl. chronic kidney failure. Screening of hypertension by measurement of blood pressure at office visits has found support in many guidelines. In clinical studies the extent of proteinuria correlates with the faster decline of glomerular filtration rate in patients with chronic renal diseases. Therefore, strict monitoring of proteinuria helps in the optimal management of patients.

Risk groups of chronic kidney disease are the follows:

- Patients with a family history of diabetes, hypertension

- $\quad$ Diabetics

- $\quad$ Hypertensive patients

- $\quad$ Recurrent urinary tract infections

- Urinary obstruction

- Patients with systemic diseases that affect kidneys

- Patients with past or family history of cardiovascular disease

The most widely used methods for screening for kidney disease are: 1) an analysis of a random urine sample for albuminuria and, 2) a serum creatinine measurement to calculate an estimated GFR, which is an indication of functioning kidney mass. It is recommendable to use both of these methods as significant kidney disease can present with diminished GFR or proteinuria, or both (Garg, Kiberd et al. 2002). Detecting and quantitation of proteinuria are essential to the diagnosis and treatment of CKD. Albumin, the predominant protein excreted by the kidney in most types of renal diseases, can be detected by urine dipstick testing. The protein-creatinine ratio in an early-morning random urine sample correlates 
well with 24-hour urine protein excretion and is much easier to obtain (2002). Albuminuria often heralds the onset of diabetic nephropathy, thus this sample is therefore recommended for all patients at risk for kidney disease. The quantitative determination of protein in the urine in the laboratory is more economical and more correct, than the use of microalbuminuria dipsticks and should be the recommended method to detect proteinuria. The term "albuminuria" should be substituted for the terms "microalbuminuria" and "macroalbuminuria." These terms are commonly used but should be avoided because they are misleading (2005). Increased urinary excretion of albumin is the earliest manifestation of CKD due to diabetes, other glomerular diseases and hypertensive nephrosclerosis. Also, albuminuria may also accompany tubulointerstitial diseases, polycystic kidney disease and kidney disease in transplant recipients.

Significant kidney dysfunction may be present despite a normal serum creatinine level. An estimated GFR based on serum creatinine level correlates better with direct measures of the GFR and detects more cases of CKD than does the serum creatinine level alone. Clinically useful GFR estimates are calculated from the measured serum creatinine level after adjustments for age, sex and race (Cockcroft and Gault 1976; Levey, Bosch et al. 1999). The two most commonly used formulas for GFR estimation are the MDRD (Modification of Diet in Renal Disease) study equation and the Cockcroft-Gault equation (Table 2). Validation studies in middle-aged patients with CKD showed the MDRD study equation to be more accurate (Levey, Bosch et al. 1999). However, the MDRD study equation was found to systematically underestimate the GFR in patients without CKD. It is important to realise that the methodology used for determination of serum creatinine is of great importance in the interpretation of the results obtained with the MDRD formula and that in fact, only the IDMScorrected serum creatinine can be used (Van Biesen, Vanholder et al. 2006). It should be kept in mind that these formulas do not result in correct GFRs when used in persons with abnormal body composition: the obese, patients with oedema, pregnancy, states of cachexia or amputees. In most situations of family doctors and as long as kidney function is stable, a calculated GFR can replace measurement of a 24-hour urine collection for creatinine clearance, that is still required in pregnant women, patients with extremes of age and weight, patients with malnutrition, patients with musculoskeletal diseases, paraplegia or quadriplegia and patients with a vegetarian diet or rapidly changing kidney function (Snyder and Pendergraph 2005). Also, creatinine clearance is preferred in predialysis and transplant patients.

\begin{tabular}{|l|l|}
\hline $\begin{array}{l}\text { Abbreviated MDRD study } \\
\text { equation (Levey, Bosch et al. 1999) }\end{array}$ & $\begin{array}{l}\text { GFR }\left(\mathrm{mL} \text { per minute per } 1.73 \mathrm{~m}^{2}\right)=186 \times\left(\mathrm{S}_{\mathrm{Cr}}\right)^{-1.154} \times \\
(\mathrm{age})^{-0.203} \times(0.742, \text { if female }) \times(1.210, \text { if black })\end{array}$ \\
\hline $\begin{array}{l}\text { IDMS traceable MDRD formula } \\
\text { (Van Biesen, Vanholder et al. } \\
\text { 2006) }\end{array}$ & $\begin{array}{l}\text { GFR }\left(\mathrm{mL} \text { per minute per } 1.73 \mathrm{~m}^{2}\right)=175 \times \\
\text { standardised } \mathrm{S}(\mathrm{Cr})^{-1.154} \times(\text { age })^{-0.203} \times(0.742, \text { if } \\
\text { female }) \times(1.212, \text { if black })\end{array}$ \\
\hline $\begin{array}{l}\text { Cockcroft-Gault equation } \\
\text { (Cockcroft and Gault 1976) }\end{array}$ & $\begin{array}{l}\text { GFR }(\mathrm{mL} / \mathrm{min} .)=(140 \text { - age }) \times \text { weight } \\
\text { female })\end{array}$ \\
\end{tabular}

GFR $=$ glomerular filtration rate; $M D R D=$ Modification of Diet in Renal Disease;

$S_{C r}=$ serum creatinine concentration $(\mu \mathrm{mol} / \mathrm{L})$;

Table 2. Estimated glomerular filtration rate mathematical formulas. 


\section{Conclusion}

Glomerular cellular changes such as platelet infiltration, mesangial cell proliferation, increased expression of proinflammatory cytokines and growth factors, as well as tubulointerstitial changes that occur early in the development of the remnant kidney progression and other models of chronic renal insufficiency, were linked to the later development of kidney fibrosis. Nowadays, there is evidence that RAS inhibition, besides the effects on glomerular hemodynamics, influence other pathogenic mechanisms of progressive renal insufficiency, e.g. hypertrophy, proteinuria, hyperlipidemia, kidney growth, infiltration of macrophages, expression of proinflammatory cytokines, etc. As previously shown in animal and clinical studies, RAS blocking agents effectively affect those pathogenetical processes of the progression of renal disease which are not unique but are similar for certain nephropathy, and, therefore, deserve to be referred to as renoprotection drugs. This is a new concept that came together with the introduction of ACEI in the mid1980s in conjunction with their effect on glomerular hemodynamics in experimental settings and, later, in clinical works.

In human chronic renal diseases, the RAS blocking therapy can arrest the decline of the GFR in diabetics and non-diabetics. When to start the treatment and which dose to choose? The optimal dose has not been determined yet. In experimental studies, optimal dosing and timing the treatment is easy to determine. In the cases of human chronic renal diseases where the onset of the disease is often insidious and at the time of renal biopsy the disease is often already advanced, uncertainty still persists with respect to the relative indications for early RAS blockade, especially if the patient does not have hypertension. A better understanding of the pathomechanisms of renal disease progression may allow us to develop more precise laboratory tests for early diagnosis of various nephropathies. Thus, usage of protein and gene expression techniques in renal biopsies or new serum or urine tests may afford, in future probably, more accurate detection of early renal alterations. Today we have mainly descriptive data about the relevance of these factors in human chronic renal diseases and much work waits before molecular diagnosis becomes available. Knowledge about the pathogenesis of renal disease progression, the use of more precise methods for evaluating renal disease evolution and the determination of the disease stage may lead to better control of the progression of renal disease in future and, as a result, reduce the number of patients reaching end-stage renal failure.

\section{References}

"ERA-EDTA registry annual report." http://www.era-edta-reg.org/index.jsp?p=annrep.

"Finnish Registry for Kidney Diseases."

http://www.musili.fi/fin/munuaistautirekisteri/finnish_registry_for_kidney_diseases/.

"UK Chronic Kidney Disease Guideline." http://www.renal.org/eGFR/eguide.html.

"UK Renal Registry." http://www.renalreg.com/.

"United States Renal Data System." http//www.usrds.org.

(2002). "K/DOQI clinical practice guidelines for chronic kidney disease: evaluation, classification, and stratification." Am J Kidney Dis 39(2 Suppl 1): S1-266.

(2005). "KD:IGO Position Statement." http://www.nature.com/isn/education/guidelines/isn/full/ed_051027_3.html. 
Anderson, S., T. W. Meyer, et al. (1985). "Control of glomerular hypertension limits glomerular injury in rats with reduced renal mass." J Clin Invest 76(2): 612-9.

Brenner, B. M. and S. Anderson (1992). "The interrelationships among filtration surface area, blood pressure, and chronic renal disease." J Cardiovasc Pharmacol 19 Suppl 6: S1-7.

Brenner, B. M., M. E. Cooper, et al. (2001). "Effects of losartan on renal and cardiovascular outcomes in patients with type 2 diabetes and nephropathy." N Engl J Med 345(12): 861-9.

Brenner, B. M., T. W. Meyer, et al. (1982). "Dietary protein intake and the progressive nature of kidney disease: the role of hemodynamically mediated glomerular injury in the pathogenesis of progressive glomerular sclerosis in aging, renal ablation, and intrinsic renal disease." N Engl J Med 307(11): 652-9.

Cockcroft, D. W. and M. H. Gault (1976). "Prediction of creatinine clearance from serum creatinine." Nephron 16(1): 31-41.

Devaraj, S. and I. Jialal (1996). "Oxidized low-density lipoprotein and atherosclerosis." Int J Clin Lab Res 26(3): 178-84.

Diamond, J. R. (1991). "Analogous pathobiologic mechanisms in glomerulosclerosis and atherosclerosis." Kidney Int Suppl 31: S29-34.

Floege, J., M. W. Burns, et al. (1992). "Glomerular cell proliferation and PDGF expression precede glomerulosclerosis in the remnant kidney model." Kidney Int 41(2): 297-309.

Garg, A. X., B. A. Kiberd, et al. (2002). "Albuminuria and renal insufficiency prevalence guides population screening: results from the NHANES III." Kidney Int 61(6): 2165-75.

Gregorio, T., B. Obrador, et al. (2007). "Epidemiology of chronic kidney disease and screening recommendations. 2007." UpToDate 15.3.

Hostetter, T. H., J. L. Olson, et al. (1981). "Hyperfiltration in remnant nephrons: a potentially adverse response to renal ablation." Am J Physiol 241(1): F85-93.

Jager, K. J. and P. C. van Dijk (2007). "Has the rise in the incidence of renal replacement therapy in developed countries come to an end?" Nephrol Dial Transplant 22(3): 678-80.

Kato, S., V. A. Luyckx, et al. (1999). "Renin-angiotensin blockade lowers MCP-1 expression in diabetic rats." Kidney Int 56(3): 1037-48.

Klag, M. J., P. K. Whelton, et al. (1996). "Blood pressure and end-stage renal disease in men." N Engl J Med 334(1): 13-8.

Klahr, S., G. Schreiner, et al. (1988). "The progression of renal disease." N Engl J Med 318(25): 1657-66.

Levey, A. S., J. P. Bosch, et al. (1999). "A more accurate method to estimate glomerular filtration rate from serum creatinine: a new prediction equation. Modification of Diet in Renal Disease Study Group." Ann Intern Med 130(6): 461-70.

Levey, A. S., K. U. Eckardt, et al. (2005). "Definition and classification of chronic kidney disease: a position statement from Kidney Disease: Improving Global Outcomes (KDIGO)." Kidney Int 67(6): 2089-100.

Lewis, E. J., L. G. Hunsicker, et al. (1993). "The effect of angiotensin-converting-enzyme inhibition on diabetic nephropathy. The Collaborative Study Group." N Engl J Med 329(20): 1456-62.

Lloyd, C. M., A. W. Minto, et al. (1997). "RANTES and monocyte chemoattractant protein-1 (MCP-1) play an important role in the inflammatory phase of crescentic nephritis, but only MCP-1 is involved in crescent formation and interstitial fibrosis." J Exp Med 185(7): 1371-80. 
Locatelli, F., M. D'Amico, et al. (2001). "The epidemiology of end-stage renal disease in the Baltic countries: an evolving picture." Nephrol Dial Transplant 16(7): 1338-42.

Maschio, G., D. Alberti, et al. (1996). "Effect of the angiotensin-converting-enzyme inhibitor benazepril on the progression of chronic renal insufficiency. The AngiotensinConverting-Enzyme Inhibition in Progressive Renal Insufficiency Study Group." N Engl J Med 334(15): 939-45.

Moeller, S., S. Gioberge, et al. (2002). "ESRD patients in 2001: global overview of patients, treatment modalities and development trends." Nephrol Dial Transplant 17(12): 2071-6.

Mogensen, C. E., W. F. Keane, et al. (1995). "Prevention of diabetic renal disease with special reference to microalbuminuria." Lancet 346(8982): 1080-1084.

Niemir, Z. I., H. Stein, et al. (1995). "PDGF and TGF-beta contribute to the natural course of human IgA glomerulonephritis." Kidney Int 48(5): 1530-41.

Noh, J. W., R. Wiggins, et al. (1993). "Urine transforming growth factor-beta activity is related to the degree of scarring in crescentic nephritis in the rabbit." Nephron 63(1): 73-8.

Noronha, I. L., Z. Niemir, et al. (1995). "Cytokines and growth factors in renal disease." Nephrol Dial Transplant 10(6): 775-86.

O'Donnell, C. J., P. M. Ridker, et al. (1997). "Hypertension and borderline isolated systolic hypertension increase risks of cardiovascular disease and mortality in male physicians." Circulation 95(5): 1132-7.

Orth, S. R. (2000). "Smoking--a risk factor for progression of renal disease." Kidney Blood Press Res 23(3-5): 202-4.

Ots, M., H. S. Mackenzie, et al. (1998). "Effects of combination therapy with enalapril and losartan on the rate of progression of renal injury in rats with 5/6 renal mass ablation." J Am Soc Nephrol 9(2): 224-30.

Ots, M., U. Pechter, et al. (2000). "Characteristics of progressive renal disease." Clin Chim Acta 297(1-2): 29-41.

Pannu, N. and P. F. Halloran (2001). " The kidney in aging " Primer in Kidney Diseases 3rd ed.

Post, T. W. and M. D. Rose (2007). "Overview of the management of chronic kidney disease in adults." UpToDate 15.3.

Raij, L. (1991). "Hypertension, endothelium, and cardiovascular risk factors." Am J Med 90(2A): 13S-18S.

Raines, E. W. and R. Ross (1997). "Is overamplification of the normal macrophage defensive role critical to lesion development?" Ann N Y Acad Sci 811: 76-85; discussion 85-7.

Remuzzi, G., P. Ruggenenti, et al. (1997). "Understanding the nature of renal disease progression." Kidney Int 51(1): 2-15.

Ross, R. (1986). "The pathogenesis of atherosclerosis--an update." N Engl J Med 314(8): 488-500.

Rubin, B., M. J. Antonaccio, et al. (1978). "Captopril (SQ 14,225) (D-3-mercapto-2methylpropranoyl-L-proline): a novel orally active inhibitor of angiotensinconverting enzyme and antihypertensive agent." Prog Cardiovasc Dis 21(3): 183-94.

Schiller, B. and J. Moran (1997). "Focal glomerulosclerosis in the remnant kidney model--an inflammatory disease mediated by cytokines." Nephrol Dial Transplant 12(3): 430-7.

Snyder, S. and B. Pendergraph (2005). "Detection and evaluation of chronic kidney disease." Am Fam Physician 72(9): 1723-32. 
Zoccali, C., A. Kramer, et al. "Epidemiology of CKD in Europe: an uncertain scenario." Nephrol Dial Transplant 25(6): 1731-3.

Zoja, C., M. Abbate, et al. (2006). "Progression of chronic kidney disease: insights from animal models." Curr Opin Nephrol Hypertens 15(3): 250-7.

Zoja, C., P. B. Garcia, et al. (2009). "The role of chemokines in progressive renal disease." Front Biosci 14: 1815-22.

Wagner, J., M. Drab, et al. (1994). "PCR analysis of human renal biopsies--renin gene regulation in glomerulonephritis." Kidney Int 46(6): 1542-5.

Van Biesen, W., R. Vanholder, et al. (2006). "The importance of standardization of creatinine in the implementation of guidelines and recommendations for CKD: implications for CKD management programmes." Nephrol Dial Transplant 21(1): 77-83.

Williams, J. D. and G. A. Coles (1994). "Proteinuria--a direct cause of renal morbidity?" Kidney Int 45(2): 443-50.

Yamamoto, T., N. A. Noble, et al. (1994). "Sustained expression of TGF-beta 1 underlies development of progressive kidney fibrosis." Kidney Int 45(3): 916-27. 


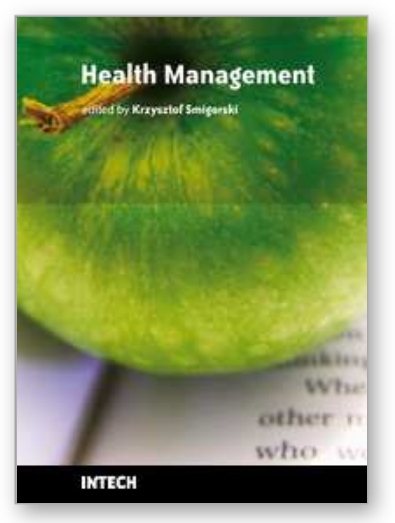

\author{
Health Management \\ Edited by Krzysztof Smigorski
}

ISBN 978-953-307-120-6

Hard cover, 112 pages

Publisher Sciyo

Published online 27, September, 2010

Published in print edition September, 2010

Possibilities of medical intervention have thrived over the last decades. Our knowledge about mechanisms of the development of diseases and factors influencing it has increased. Effective treatment requires a holistic approach that takes into consideration aspects at first sight not related to a course of a specific disorder. This book contains a few chapters focusing on issues related to health management. The chapters are arranged in an order reflecting multidimensionality of issues constituting this theoretical and practical area - starting from the studies focusing on a general, administrative level, to considerations related to situations of individuals suffering from a specific illness. The discussed problems concern different age groups - children, adults and the elderly. We hope that readers professionally engaged in healthcare - both theoretically and clinically - will find it interesting, useful and inspiring.

\title{
How to reference
}

In order to correctly reference this scholarly work, feel free to copy and paste the following:

Mai Ots Rosenberg (2010). Chronic Kidney Disease, Health Management, Krzysztof Smigorski (Ed.), ISBN: 978-953-307-120-6, InTech, Available from: http://www.intechopen.com/books/healthmanagement/management-of-chronic-kidney-disease

\section{INTECH}

open science | open minds

\section{InTech Europe}

University Campus STeP Ri

Slavka Krautzeka 83/A

51000 Rijeka, Croatia

Phone: +385 (51) 770447

Fax: +385 (51) 686166

www.intechopen.com

\section{InTech China}

Unit 405, Office Block, Hotel Equatorial Shanghai

No.65, Yan An Road (West), Shanghai, 200040, China 中国上海市延安西路65号上海国际贵都大饭店办公楼 405 单元

Phone: +86-21-62489820

Fax: $+86-21-62489821$ 
(C) 2010 The Author(s). Licensee IntechOpen. This chapter is distributed under the terms of the Creative Commons Attribution-NonCommercialShareAlike-3.0 License, which permits use, distribution and reproduction for non-commercial purposes, provided the original is properly cited and derivative works building on this content are distributed under the same license. 